\title{
Trends and Topics in Research and Development Related to the Improvement of Signalling and Telecommunication Systems Using Information and Communication Technology
}

\author{
Kunihiro KAWASAKI \\ Signalling and Transport Information Technology Division
}

\begin{abstract}
The purpose of the signalling and transport information division is to contribute to enhanced railway safety, reliability, and convenience through research and development into signalling systems, communication network technology, transportation planning and traffic operations technology, and condition monitoring technology for railway facilities. This paper outlines trends in research and development on improving the safety and availability of signalling systems and telecommunication systems using Information and Communication Technology (ICT) such as image analysis, artificial intelligence, cloud computing, and mobile communications networks.
\end{abstract}

Keywords: ICT, image analysis, machine learning, information network, signalling safety facilities, radio train control

\section{Introduction}

The past years have seen a dramatic improvement in computational ability of computers, falling prices of highcapacity memory, and increase in the speed of mobile communications notably with mobile phones and wireless LANs, creating an environment in which massive amounts of data can be transmitted, stored, and processed. In fields such as entertainment, publishing, and education, Information and Communication Technology (ICT) is utilized to develop services and products, that have become part of our everyday life. In industry, ICT is being applied to improve safety, reliability, and productivity or to create innovative products and services that were not possible before.

The impact of ICT is expected to be seen in the railways too: as a tool to make safer systems that can be operated with fewer personnel and at lower costs than before. The Railway Technical Research Institute (hereinafter RTRI) is researching and developing (hereinafter referred to as "R\&D" ) new systems and inspection and evaluation methods, that apply ICT, in various technical fields such as vehicles, structures, electrical power, tracks, disaster prevention, signalling and information, and human science.

This article describes recent trends in research and the future direction of $\mathrm{R} \& \mathrm{D}$, focusing on train operation control systems. It also introduces a system established to promote research on ICT utilization in a unified, cross-cutting, and speedy manner throughout RTRI in the future.

\section{Overview and ICT trends}

\subsection{Purposes and impact of using ICT}

The term "ICT" was coined by combining Information, Technology and Communication. The English word "Communication," which is often translated as "Tsushin" in Japanese, originated from the Latin word "Communis," meaning "shared understanding of information and ideas." The essence of ICT, therefore, is not only to transmit and process sensor data but also to enable sharing of information that exists as analogue quantities in various forms in real space by transmitting and collecting them in digitized form, and then feeding them back to real space, and then sharing the results of analyses and forecasts through IT. One example of ICT utilization in the case of a control system for facilities, is with data measured by various sensors which is collected through an information network and put through Big Data processing and other advanced information processing using AI, etc. Actuators are then controlled on the basis of the outcome of analyses or forecasts.

ICT can be used for a wide variety of tools depending on the combination of four component technologies: sensing, transmission and storage, information processing, and display and control. Sensing is achieved by vibration and other sensors that convert physical quantities into electrical signals. A camera is also a type of sensor that can provide a vast amount of information. Typical examples of IT include image analysis technology, Big Data analysis technology, and artificial intelligence based on machine learning technology, which is rapidly evolving. The most likely effect of ICT expected in the industrial sector include labor saving and automation of work done by humans, improvement of reliability through reduction of mistakes, and substitution for work that cannot be performed by humans.

\subsection{Japan's goal to build a Society 5.0}

Society now, is known as the "information society." Human intervention is often required, for example, to input information from the real world into computer networks, i.e., cyber space, or retrieve information in cyber space and use it in the real world. In other words, cyber and real space are isolated from each other. Unless cyber space is accessed by people, no information can be input or output. Furthermore, data is often collected or shared separately in each industry or even in each business or technical field in an industry. The "Future Investment Strategy 2017" [1] approved by the Japanese government in 2017 aims to shift the current society ( "Society 4.0" ) to a "super-smart society" ( "Society 5.0" ) that achieves a sophisticated fusion of cyber and real space, where all kinds of information about status are accumulated in cyber space using sensing technology and the Internet of Things (IoT) to allow value- 
added information based on the AI-based analysis and forecast results to be fed back to real space. Once Society 5.0 is realized, status information will be automatically entered into cyber space and shared across industries and business fields, eliminating gaps between regions and ages, enabling supply of things and services that meet needs, and solving social issues such as an aging population and energy issues, whilst also driving economic development.

\section{Train operation control and ICT}

\subsection{ICT utilization for train operation control}

Safety and stability of train operation today, is achieved using two systems: Train operation control systems and safety signalling systems. The train operation control system ensures timely operation of trains according to timetables and adjustments to operations in case of delays; whereas safety signalling systems ensure the safety of trains using safety control equipment, etc. Studies are currently underway to find labor-saving methods and automation solutions using ICT for both systems, to reduce the number of facilities or enable operations to be controlled with fewer personnel. Furthermore, a radio sensor network is being developed to identify the status of field devices and a method being devised to forecast equipment malfunctions using information processing technologies such as data analysis and machine learning.

At present, a typical example of the practical application of ICT to train operation control in and out of Japan are radio train control systems. This type of system, using radio communication and database technologies, controls trains safely while collecting detailed information such as position and speed of trains. It is being introduced in many countries in the world. In Japan, the entry into service of ATACS by JR East set a trend that has been followed by other railway operators that are now examining and developing their own systems.

The advantage of a radio train control system include a smaller amount of equipment required to secure fixed blocks, and flexible setting of train intervals. It can also be utilized as a base system for more advanced train control systems that provide predictive control, automated driving, etc.

A radio train control system, although not connected to the Internet, is a sort of IoT in the broad sense if it is considered that target objects, i.e., trains, point machines, and crossings, are "things" (Fig. 1). The IoT is a system that connects equipment and devices, i.e., "things" directly to an information network, that enables the sharing of status data of each item in the network, and that allows the things to be controlled on the basis of the processing and analysis of wide-ranging data. This is one example of ICT utilization, where status information is collected and equipment is controlled without human intervention. While Japan does not yet use this type of system, other countries have radio train control systems that utilize IP-based radio communication networks. Therefore, even without an Internet connection, Internet technologies are already in use. The fifth-generation mobile communication network called " $5 \mathrm{G}$ " will start service by the end of 2018 in some countries

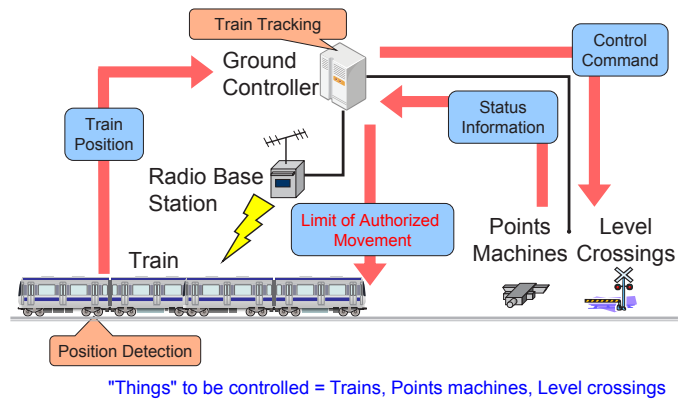

Fig. 1 Radio communication based train control system

and by 2020 in Japan [2]. 5G technology will enable transmission of information that will require high security, the radio train control system communication networks may be replaced with the Internet, becoming one of the implementation of a large scale Internet of Things.

\subsection{Future vision of new operation control system through integration of train operation control and safety control}

The radio train control system described in Section 3.1 makes it possible to acquire detailed information about train position, speed, etc. If train performance curves can be created using this detailed information, it is hoped that a new operation control system can be designed that guarantees safety with timetable control. When this type of system is made a reality it will be flexible enough to adapt train operations to circumstances, such as passenger concentration and train delays, thus preventing delay extension and ensuring early recovery from timetable disruptions. RTRI has therefore been working since FY2015 on the development of such a system that integrates train operation control and safety control using an information network, by recalculating train performance curves in real time and controlling individual trains and their routes [3]. The key basis for this system is the information network. If an information network carries not only train control information but also status information from wayside sensors and control equipment and information from ticket gates, the system can digitize all railway operation statuses, facility statuses, flow of passengers, etc. and can share them as data. This would allow the operational status of the entire railway system to be captured and accessed by administrative and other relevant departments. The ability to virtually reproduce or make forecasts, using a computer, on the basis of certain sets of conditions and train operation statuses based on this data, would reduce the manpower required to identify these statuses and alleviate the workload for operations and maintenance in disrupted situations (Fig. 2) [4]. This is, so to speak, a railway-version Cyber Physical System. If trains are able to run autonomously and railway facilities able to autonomously transmit information on defective parts, replacement dates, etc. it would be possible to design a system close to the one corresponding to a Society 5.0 described in Section 2.2.

Similar research is also underway in other countries. For example, SNCF currently has a project to develop trains that would be able to run autonomously by FY2023. 


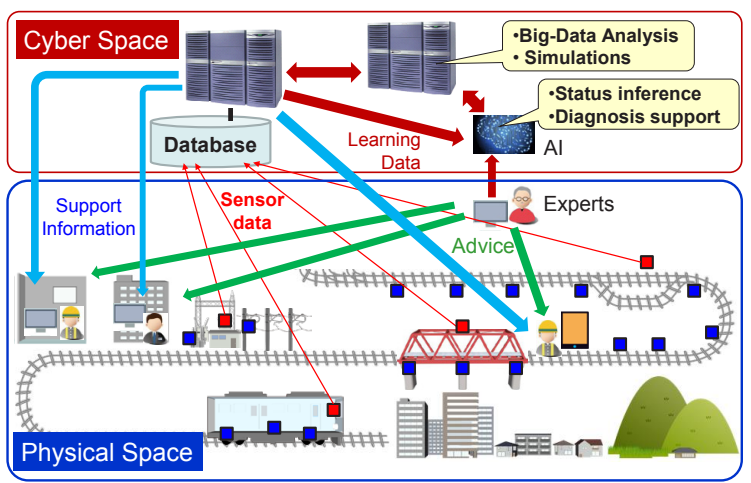

Fig. 2 Railway-version Cyber Physical System

\subsection{Outlook for radio communications networks in the railways}

One key issue in the development of ICT for railways is the securing of communication resources. Particularly for track/train radio communications, because conventional demand for low-capacity and high-reliability transmission is increasing, as well as the need for high-capacity transmissions. The most commonly used frequency used in the railways at present is the UHF band, however, available UHF bands are running short. As such, the use of the EHF bands is being investigated because of the possibility that it could offer wider bands allowing multiple channels. Recent developments in low-cost and high-performance semiconductor devices and progress in RoF (Radio on Fiber) technology, which transmits radio frequency electric signals over optical fiber cables, have made it possible to construct a low-cost EHF-based track-to-train communication system [5]. EHF-based train radio, if brought into service, would improve driving efficiency, quality of passenger services or enable the introduction of new traffic control methods, which have so far not been possible. Furthermore, it is considered that new public networks and general-purpose radio communication technologies such as $5 \mathrm{G}$, which are about to come into service, could be leveraged as a means to ensure safer and more stable train operations.

However, certain issues must be overcome, such as interference resistance or communication quality stability, to ensure that information for which high reliability and stability are required can be transmitted without fail if necessary. RTRI is researching and developing a high-capacity and high-reliability radio communication network for railways by seamlessly linking multiple radio communication media (Fig. 3).

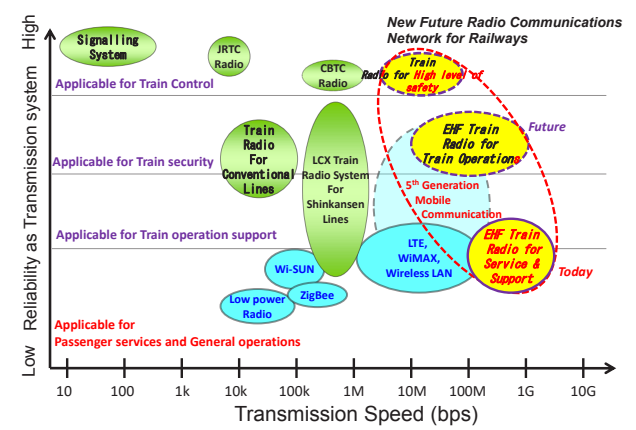

Fig. 3 Outlook for radio communications in the railways

\section{Research on future use of ICT}

\subsection{ICT Innovation Projects at RTRI}

R\&D on ICT application at RTRI is being carried out in all its technical fields, and is producing practical results that have been applied to reduce labor intensity and introduce automation in some processes.

However, in order to arrive at a new railway system based on innovative ICT within a reasonable time frame, it is recognized that multidisciplinary technical know-how must be pooled and combined with a cross-cutting R\&D approach.

Therefore, the "ICT Promotion Team" was launched in June 2017 as the foundation for establishing strategies and implementation plans that would allow RTRI to carry out R\&D on ICT use in a unified, systematic, and timely manner. The ICT Promotion Team surveyed ICT trends, examined technologies and ideas that could contribute to solving problems and designing innovative business models in the railways. They then identified issues to be addressed by RTRI, examined the direction of R\&D on ICT use, and, in December, finalized a set of recommendations for future R\&D. These directions include (1) improvement of train operation safety, (2) train operation automation, (3) automation of maintenance, and (4) establishment of common core technologies for railways.

Based on output of the ICT Promotion Team, RTRI launched an "ICT Innovation Project" in April 2018 as a roadmap for $R \& D$ that accurately reflects the future rapid progress of ICT and the needs of railway operators for solutions to current problems and new business models. The purpose of the Project is to chart out an implementation plan for feasible cross-cutting R\&D that can be applied to railways.

The Project not only identifies individual R\&D challenges, it also maps out overall implementation plans to overcome these challenges in pursuit of the R\&D goals determined by the ICT Promotion Team. In addition, it will examine possible paths of future ICT research and will provide a draft plan of new, cross-cutting R\&D themes. In addition, the Project will also identify commonality of challenges in implementing the R\&D themes related to ICT, and propose methods for pooling know-how and tools generated in the course of $R \& D$.

\subsection{Signalling \& Transport Information Technology Division work}

As mentioned above, R\&D on ICT use is part of the work carried out in all technical fields. Image analysis technology and information technology (IT), such as Big Data processing and artificial intelligence (AI), in particular are areas where innovation is happening very fast. If R\&D continues in isolated fashion in each technical area, there is a risk therefore of falling behind. An "Image Analysis and IT Laboratory" was therefore established as part of the Signalling \& Transport Information Technology Division in December 2017 to bring together knowledge on image analysis technologies and IT utilization, that existed in individual technical fields such as facilities, electric equipment, vehicles, and ergonomics, to optimize RTRI's techni- 
Table 1 New R\&D themes output by the ICT Promotion Team

\begin{tabular}{|c|c|c|}
\hline R\&D Direction & Theme headings & $\begin{array}{l}\text { Fiscal year of } \\
\text { implementation }\end{array}$ \\
\hline $\begin{array}{l}\text { (1) Improvement of train } \\
\text { operations safety } \\
\text { (2) Automation of train } \\
\text { operations }\end{array}$ & $\begin{array}{l}\text { On-board obstruction detection method } \\
\text { using sensor fusion system }\end{array}$ & 2018 to 2020 \\
\hline $\begin{array}{l}\text { (3) Automation of } \\
\text { maintenance }\end{array}$ & $\begin{array}{l}\text { Research on methods to determine deterioration } \\
\text { of individual components using multi spectral } \\
\text { image analysis }\end{array}$ & 2018 to 2019 \\
\hline $\begin{array}{l}\text { (4) Development of common } \\
\text { core technologies }\end{array}$ & $\begin{array}{l}\text { Research on unification of positioning } \\
\text { information of railway facilities }\end{array}$ & 2018 to 2019 \\
\hline
\end{tabular}

cal capability and accelerate this area of R\&D. The Image Analysis and IT Laboratory not only works on upgrading image analysis technology and IT to be applied to railways, but also researches and develops applications for image analysis technology, to monitor the status of facilities and crew support during train operation, and finds ways to apply IT to improve maintenance efficiency, train operation control, etc. The Image Analysis and IT Laboratory is staffed by 13 members including its director. 10 of the staff are also members of the Vehicle Structure Technology Division, Vehicle Control Technology Division, Structure Technology Division, Track Technology Division, Power Supply Technology Division, Railway Dynamics Division, and Human Science Division. The Laboratory also serves as a forum for open discussion not only among laboratory members but also among researchers from various technical fields who are interested in imaging and IT.

The Imaging and IT Laboratory took on eight R\&D themes in FY2018, including three new themes proposed by the ICT Promotion Team (Table 1). The Signalling \& Transport Information Technology Division has 36 R\&D themes as of FY2018, 20 of which concern ICT utilization. RTRI will continue its work on ICT use, taking into account the inherent characteristics and environmental conditions of railways. The IT Laboratory will take the lead on the "IT" in ICT in new Imaging, while the " $\mathrm{C}$ " in ICT will be under the leadership of the Telecommunications and Networking Laboratory in collaboration with other related technology divisions and laboratories in RTRI and experts from railway operators, research institutions, manufacturers, and universities.

\section{Conclusion}

This article gives an overview of current R\&D focused on signalling and telecommunication system innovation based on ICT use, and describes the outlook for this sector. ICT is not only an indispensable tool in maintaining railways but also a powerful tool for further development.
Application of ICT in the railways however, depends on being able to adapt the technologies so that they can be used appropriately in the railways to ensure safety and reliability - it is not simply a question of applying technology. Other important issues include the creation of standards and guidelines to determine which technologies can be used, and establishment of evaluation methods to understand the impact of ICT use. Furthermore, cyber security must also be addressed. For signalling and telecommunications in particular, it is vital to find means to keep systems running and avoid loss of service wherever possible while maintaining safety and to devise specific control methods. The utilization of ICT for railways is just beginning. The authors of this paper are confident that new technologies and systems can be made a reality if multiple organization tackle these challenges from various angles, by competing and working together. Future plans aim to foster practical R\&D while collaborating with railway operators and research institutions, manufacturers, and universities on advanced technologies, to achieve results that contribute to the progress of and maintaining the railways.

\section{References}

[1] Prime Minister of Japan and His Cabinet web-site, https://www.kantei.go.jp/jp/singi/keizaisaisei/kettei. html\#tousi2017 (English version).

[2] Ministry of Internal Affairs and Communications, WHITE PAPER Information and Communications in Japan Year 2017, Ministry of Internal Affairs and Communications, 2017 (English version).

[3] S. Hiraguri, "Recent Research and Development of Signalling and Telecommunications Technologies," RTRI Report, Vol. 30, No. 1, pp. 1-4, 2016 (in Japanese).

[4] K. Kawasaki, K. Nakamura, "Trend of the Development of Millimeter Wave Technology for Railway Applications," RTRI Report, Vol. 30, No. 1, pp. 51-54, 2016 (in Japanese).

\section{Author}

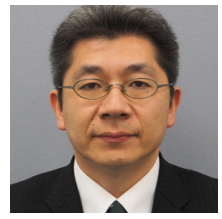

Kunihiro KAWASAKI

Director, Head of Signalling and Transport

Information Technology Division

Research Areas: Radio Communication

System, Radio Propagation, Electro Magnetic

Compatibility 